\title{
NEUROLOGY IN PRACTICE: CEREBROVASCULAR DISEASE
}

I Bone, G N Fuller

troke medicine has evolved dramatically over the last 20 years. The major advances have

$\circlearrowleft$ arisen from large clinical trials, combining studies using meta-analysis, improved classification of stroke subtypes, and developments in investigation, particularly imaging. Of all branches of neurology, stroke is where clinical decisions are most solidly based on evidence from clinical trials. One important factor has been the collaboration both internationally and between the different clinical disciplines involved in care of stroke patients.

In North America and in most European countries neurologists are involved in the care of the majority of stroke patients, whereas currently in the UK involvement is more limited. Regardless of whether a trainee develops stroke as a subspecialty interest or not, cerebrovascular disorders are common and a significant component of general neurological practice. It is therefore important to be aware of the developments within stroke medicine.

This supplement begins with an outline of "Assumed knowledge", with a personal selection of key references to provide a background to the respective areas. In addition we have included details of some important sources of information that will be helpful starting points to answer specific clinical questions and to review the evidence underlying current practice. Trainees are encouraged to review the references given in the supplement articles.

The supplement is not comprehensive. We have not included rehabilitation, as it will be the subject of a later edition.

\section{ASSUMED KNOWLEDGE}

Anatomy

- Arterial territories of the human brain: cerebral hemispheres. Tatu L, Moulin T, Bogousslavsky J, et al. Neurology 1998;50:1699-708.

- Arterial territories of the human brain: brain stem and cerebellum. Tatu L, Moulin T, Bogousslavsky J, et al. Neurology 1996;47:1125-35.

These references provide practical tools for determining arterial territories on CT and MR images.

\section{Classification}

- Classification of sub types of acute ischaemic stroke. Definitions for use in a multicentre clinical trial (TOAST). Trial of Organon 10172 in acute stroke treatment. Adams HP, Bendixen BH, Cappell E, et al. Stroke 1993;24;35-41.

- Classification and natural history of clinical sub types of cerebral infarction. Bamford J, Sandercock P, Dennis M, et al. Lancet 1991;337:1521-6.

These two papers provide the basis for the syndromic classification of stroke that has been used in recent large stroke trials.

\section{Measuring stroke}

- A comparison of neurological scales and scoring systems for acute stroke prognosis. Muir KW, Weir CJ, Murray GD, et al. Stroke 1996;27:1817-20.

This paper compares commonly used stroke scales and scoring systems, giving key references.

\section{Guidelines}

- Intercollegiate Working Party for Stroke. National clinical guidelines for stroke. London: Royal College of Physicians, 2000.

Correspondence to: Professor I Bone, Department of Neurology, Institute of Neurological Sciences, Southern General Hospital, 1345 Govan Road, Glasgow G51 4TS, UK

Dr G N Fuller, Department of Neurology, Gloucester Royal Hospital, Great Western Road, Gloucester GL1 3NN, UK

- Scottish Intercollegiate Guideline Network (SIGN). Management of patients with stroke 1. Assessment, investigation, immediate management and secondary prevention. Edinburgh: SIGN publication number 13, 1997.

- Royal College of Physicians of Edinburgh. Consensus conference on atrial fibrillation in hospital and general practice. Consensus statement. Proc R Coll Phys Edin 1998;28:552-4.

- Guidelines for the management of hypertension. Report of working party of the British Hypertension Society. Ramsay LE, Williams B, Johnston GD. J Hum Hypertens 1999;13:569-92.

- Consensus conference on lipid lowering to prevent vascular events. Proc $R$ Coll Phys Edin 1999;29(suppl 5).

- Guidelines for carotid endarterectomy. Special writing committee of the Stroke Council, American Heart Association. Circulation 1998;97:501-9.

These guidelines provide a foundation for good clinical practice. 


\section{Cochrane corner}

- Anticoagulants for preventing stroke in patients with non rheumatic atrial fibrillation and a history of stroke or transient ischaemic attacks. Koudstaal PJ.

- Thienopyridine derivatives (ticlopidine, clopidogrel) versus aspirin for preventing stroke and other serious vascular events in high vascular risk patients. Hankey GJ, Sudlow CLM, Dunbabin DW.

- Carotid endarterectomy for asymptomatic carotid stenosis. Chambers BR, You RX, Donnan GA.

- Carotid endarterectomy for symptomatic carotid stenosis. Cina CS, Clase CM, Haynes RB.

- Antiplatelet therapy for acute ischaemic stroke. Gubitz G, Sandercock P, Counsell C.

- Anticoagulants for acute ischaemic stroke. Gubitz G, Counsell C, Sandercock P, Signorini D.

- Interventions for deliberately altering blood pressure in acute stroke. Blood pressure Acute Stroke Collaboration (BASC).
- Thrombolysis for acute ischaemic stroke. Wardlaw JM, del Zoppo G, Yamaguchi T.

- Organised inpatient (stroke unit) care for stroke. Stroke Unit Trialists' Collaboration.

- Surgery for primary supratentorial intracerebral haemorrhage. Prasad K, Shrivastava A.

Source for all the above: Cochrane database of systematic reviews issue 3,2000 .

This is a selection of completed analyses from this key resource. Many of the comments in this supplement are based on the conclusions of these reviews.

$$
\star \star \star
$$

- Stroke management. Gubitz G, Sandercock P. Clinical Evidence 2000;3:107-17.

- Stroke prevention. Clinical evidence writers. Clinical Evidence 2000;3:118-34.

Clinical evidence provides a shorter paper based evidence-based resource summarising the trial base evidence found in more detail in the Cochrane database.

\section{SURFING FOR STROKE}

Exploring the internet for useful information on medical conditions can be an endlessly frustrating exercise. While many of the sites are intended as "all things to all people" the Stroke Network (http://www.strokenetwork.org/) is unusual in that it is primarily a site for patients and caregivers. Much of the tone of this site is optimistic, stressing recovery from stroke and providing sufferers with sensible advice.

The heavy weight brigade of stroke websites tends to be North American in origin (http://www.americanheart.org/ and http://www.stroke.org/). Both sites are huge and can be difficult to navigate. It not clear the level at which the information is pitched (patient or professional). The NINDS (National Institute of Neurological Disease and Stroke) site (http://www.stroke-site.org/) is aimed at the acute stroke doctor. It provides a number of treatment guidelines for acute management including administration of thrombolysis and blood pressure management in the first few hours. Useful links to commonly used rating scales for stroke severity, disability, and handicap are given. The level of evidence associated with the information given is not always clear.

The European entry to the field is EUSI (European Stroke Initiative) (http://www.eusi-stroke.com). I found this to be the most useful for a trainee and easy to navigate. The "Stroke news" section provides the latest publications on all aspects of stroke medicine-great to impress on the ward round! Searching the site is relatively easy.

A very different form of online resource is provided in the "Stroke doctor's guide to the internet" (http://www.pslgroup.com/STROKES.htm). This is a professionally set up medical site which can be adapted to your specialist interest, allowing journal updates requests and links to many of the major journal internet sites. The clinical cases section in stroke medicine is excellent and would provide a useful source for teaching material for students and residents. This is a great site to browse although registration is mandatory.

TRACEY A BAIRD

Department of Neurology, Institute of Neurological Sciences, Southern General Hospital, 1345 Govan Road,

Glasgow G51 4TS, UK tootsbaird@hotmail.com 